\title{
LA PERSISTENCIA DE UNA INCOMODIDAD: REPENSANDO EL CAMPESINADO EN LA ARGENTINA
}

\author{
A PERSISTENT DISCOMFORT: \\ RETHINKING THE PEASANTRY IN ARGENTINA
}

Pablo Barbetta ${ }^{1}$

Diego Domínguez ${ }^{2}$

Pablo Sabatino ${ }^{3}$

RESUMEN: En Argentina existe un consenso, plasmado en un andamiaje conceptual y un conjunto de políticas públicas, que produce lo campesino como inexistente o bien define las realidades campesinas en términos de carencia. Partiendo de la distancia entre los mundos de vida de un determinado sujeto agrario y el campo académico, nos volcamos aquí a una reflexión sobre la cuestión campesina en términos empíricos y teóricos, asumiendo una mirada desde la "sociología de las ausencias" (Santos, 2000). El presente artículo plantea que es pertinente retomar un concepto con vasta trayectoria en los estudios rurales: el campesino. Para ello se problematizan las formas en que dicho concepto fue caracterizado tanto desde la academia como desde los programas de intervención estatal. A la par, se propone un cambio epistémico que permita reconocer al sujeto campesino en sus discursos y prácticas: Soberanía Alimentaria, Reforma Agraria Integral, Agroecología y Justicia Ambiental dan cuenta tanto de la historicidad del sujeto como de la posibilidad de insertarlo en debates actuales que convocan a toda la sociedad.

Palabras clave: campesinado, cambio epistémico, sociología de las ausencias, políticas públicas.

\footnotetext{
${ }^{1}$ Doctor por la Universidad de Buenos Aires (mención en Antropología), Investigador Asistente Consejo Nacional de Investigaciones Científicas y Técnicas (CONICET), Instituto de Investigaciones Gino Germani, Fac. de Cs. Sociales, Universidad de Buenos Aires, Buenos Aires, DF, Argentina, e-mail: pbarbetta@sociales.uba.ar

${ }^{2}$ Doctor en Ciencias Sociales, Instituto de Investigaciones Gino Germani, Universidad de Buenos Aires (UBA), Consejo Nacional de Investigaciones Científicas y Técnicas (CONICET), Buenos Aires, DF, Argentina, e-mail: didominguez1@yahoo.com

${ }^{3}$ Sociólogo / Licenciado en Sociología. Integrante del Grupo de Ecología Política Comunidades y Derechos, Instituto de Investigaciones Gino Germani, Universidad de Buenos Aires (UBA), Buenos Aires, DF, Argentina, e-mail: pasaba2001@yahoo.com.ar
} 
ABSTRACT: In Argentina, there is a consensus, expressed in a conceptual framework and a set of public policies that produce the peasantry as nonexistent or defined the rural realities in terms of lack. Based on the distance between the worlds of life of a particular subject and agricultural academic field, we turn here to reflect on the peasant question in theoretical and empirical terms, assuming a view from the "sociology of absences" (Santos, 2000). This article argues that a concept is relevant resume with vast experience in rural studies: the peasant. We problematize the ways in which this concept was problematized both from academia and from state intervention programs. At the same time, we propose an epistemic change which recognizes the peasant subject in their discourses and practices: Food Sovereignty, Comprehensive Agrarian Reform, Agroecology and Environmental Justice realize both the historicity of the subject and the ability to insert it into current debates call for the entire society.

Keywords: peasantry, epistemic change, sociology of absences, public policy

\section{INTRODUÇÃO}

Partiendo de la distancia entre los mundos de vida de un determinado sujeto agrario y el campo académico, nos volcamos aquí a una reflexión sobre la cuestión campesina en términos empíricos y teóricos, asumiendo una mirada desde la "sociología de las ausencias" (Santos, 2000), y los efectos de teoría que estos debates tienen sobre las políticas públicas.

En efecto, debemos alertar sobre la existencia de cierto rechazo a reconocer la presencia campesina en Argentina. Desde ciertas políticas públicas, y el andamiaje conceptual que las sustenta, se ha caracterizado un tipo de sujeto agrario beneficiario que produce lo campesino como inexistente o bien define las realidades campesinas en términos de carencia.

Sin embargo, como esas noticias que llegan tarde porque nadie las cree ciertas, nos hacemos eco de aquellas que indican que hay campesinos en Argentina. En distintas provincias se encuentran po- 
blaciones que se reconocen como campesinas. Y a la vez, otro tanto se reconoce también como indígenas, es decir, campesinos que a la vez se presentan como parte de algún pueblo originario. Este proceso identitario lo observamos en el marco de una creciente conflictualidad por la tierra, y un también creciente activismo campesino visible en la emergencia de decenas de organizaciones en distintas escalas geográficas que adscriben su pertenencia al campesinado. Paralelamente a estos procesos, múltiples experiencias de producción, de comercialización, de comunicación-formación, de acceso y manejo a los bienes naturales, de procesamiento, entre otras, al mismo tiempo que dan cuenta de la presencia campesina en la arena política Argentina, ponen en jaque los supuestos epistemológicos sobre los que se construyó la ausencia campesina en términos teóricos.

En tal sentido, nos planteamos que es pertinente retomar un concepto con vasta trayectoria en los estudios rurales: el campesino. Para ello problematizamos las formas en que dicho concepto fue caracterizado tanto desde la academia como desde los programas de intervención estatal. A la par, que proponemos un cambio epistémico que permita reconocer al sujeto campesino en sus discursos y prácticas: Soberanía Alimentaria, Reforma Agraria Integral, Agroecología y Justicia Ambiental dan cuenta tanto de la historicidad del sujeto como de la posibilidad de insertarlo en los debates actuales que convocan a toda la sociedad.

En un primer apartado, sistematizamos brevemente las discusiones en torno a las conceptualizaciones que cuestionan el uso del concepto de "campesino" en la Argentina y su imbricación con las políticas públicas destinadas a dicho sujeto agrario. Al mismo tiempo recuperamos desde un cambio en nuestra posición epistemológica al sujeto campesino en sus discursos y prácticas. En el segundo apartado, destacamos la importancia de los campos de experimentación que teje el campesinado en tanto querella en torno a los modos de ser, los modos de hacer y los modos de decir. El último apartado estará dedicado a las reflexiones finales. 


\section{BREVE PASO POR LOS ESTUDIOS CAMPESINOS EN AR- GENTINA}

Podemos encontrar, en principio, dos razones a esta relativa invisibilización de la cuestión campesina en Argentina. En primer lugar, el carácter eminentemente agroexportador del país sesgó la problemática del desarrollo agrario en la Argentina y el estudio de las transformaciones sociales y productivas, hacia los procesos económicos y sociales que ocurrían en la pampa húmeda. De esta manera, dicha región, asociada a la empresa familiar capitalizada (los chacareros o colonos), se erigió como el modelo estereotipado de la estructura social agraria argentina. En este marco, la subordinación de las economías regionales a un desarrollo nacional centrado en la región pampeana supuso tanto la exclusión de regiones productivas como el silenciamiento y arrinconamiento de una heterogeneidad de sujetos sociales agrarios (campesinos, pequeños productores, trabajadores rurales, etcétera). En segundo lugar, Posadas (1997) sostiene que "no vamos a encontrar reflexiones ni discusiones del tenor de las llevadas a cabo por los campesinistas y descampesinistas mexicanos, ni un volumen de estudios de caso, como los efectuados en Ecuador o Perú" (pág. 74), ya que en ese período Argentina atravesaba por un período político dictatorial que impidió la reflexión crítica pública (Giarracca, 1990).

Situados en su mayoría en regiones "periféricas" en relación con el "centro" pampeano, el debate campesino, más allá de las especificidades de ciertos estudios de caso, partía del consenso de que los campesinos argentinos no podían ser asimilables a los campesinos latinoamericanos ni eran totalmente capitalistas, ya que se trataba de unidades que raramente se mantenían fuera del mercado, que cuando podían utilizaban mano de obra asalariada y que en la mayoría de los casos habían nacido al calor del desarrollo agroindustrial: de la caña de azúcar, del algodón, la yerba mate, el té, la vid, etcétera (Giarracca y Teubal, 2005). De esta manera, el objetivo de las ciencias sociales en relación con las unidades campesinas fue, si bien esto no significa dejar de lado la lógica interna de las unidades campesinas, 
considerar la relación entre la expansión del capitalismo y la "funcionalización" (o su disfuncionalidad, podríamos agregar nosotros) del campesinado por parte del modo de producción capitalista que lo subordina (Tsakoumagkos, 1987). Este punto de partida imposibilitó un debate teórico acerca de los rasgos que caracterizan al campesinado más allá de lo que Santos (2000) denominó como "la monocultura del monoproductivismo capitalista" que supone la idea de que el crecimiento económico y la productividad mensurada en un ciclo de producción determinan la productividad del trabajo humano o de la naturaleza. En este contexto, los cientistas sociales se dedicaron a analizar (y por supuesto, nominar) cómo las características estructurales de este sujeto al que nosotros llamamos campesino fueron variando a través de los distintos períodos históricos como consecuencia de las trasformaciones ocurridas en el modelo agropecuario.

Así durante el período conocido como "modelo de Industrialización por Sustitución de Importaciones (ISI)", el término "campesino" fue utilizado mayormente para designar a una forma de organización económica distinta de la capitalista donde prevalece el trabajo familiar y donde si bien existe venta y compra de mercancías, ésta no alcanza ningún excedente una vez terminado el ciclo productivo. Esta caracterización fue de suma importancia dentro de los estudios rurales en Argentina, en primer lugar, porque permitían diferenciar al campesinado de otro sujeto importante de la estructura agraria argentina más ligado a los sectores medios rurales, y que fuera denominado de distintas maneras, según la zona geográfica en donde están asentados: chacareros o farmers, para la región pampeana y colonos para las regiones del nordeste. De esta manera, para Francisco Delich (1972), los campesinos constituían "una cuarta clase" ubicada entre la clase media rural y los asalariados. En segundo lugar, porque esta "cuarta clase" en el agro argentino, como podría sostener Delich, se diferenciaba por poseer una racionalidad diferencial en términos económicos en relación con los otros sujetos sociales pertenecientes a la estructura agraria argentina, es decir, racionalidad caracterizada, como sostiene Chayanov, por la subsistencia y no por la obtención de una tasa normal de ganancia. 
Estos debates se verían truncados con el golpe cívico-militar de 1976, en un contexto de intensa represión a las organizaciones y experiencias políticas de las poblaciones rurales. A partir de este momento la noción y categoría de campesino fue vaciada de capacidad explicativa, hasta el punto de producir desinterés académico. Según Patricia Durand (2004) la última dictadura habría dejado huellas en la trayectoria de los conceptos como la extensión del "uso del término 'pequeño productor' para hacer referencia al mismo actor social [el campesino]". Se trataría de un primer deslizamiento que recorta el concepto dejando solamente los aspectos productivos, tanto internos de la unidad, como externos de las relaciones con la estructura agroindustrial. El uso de conceptos tales como "pequeño productor minifundista" o "pequeño productor familiar" implicó la marginación del concepto de campesino que se presentaba en forma creciente como carente de especificad, destinado al desuso por la misma naturaleza transitoria y subalterna a los procesos del capital que se le atribuía al sujeto histórico que nombraba. En todo caso, lo campesino entendido como sujeto exclusivamente productivo remitía a un proceso de creciente pérdida de condición propia, ligado a la subordinación y al dejar de ser.

El marco en que se da este deslizamiento conceptual abarca un período crítico de nuestra historia donde se abren distintos procesos. En le plano político las experiencias organizativas del campesinado son desarticuladas por la dictadura mediante la represión. A la vez que se implementa las políticas económicas neoliberales (las que se profundizarán a lo largo de los años de 1990) que produjeron un importante impacto en la estructura social agraria y en la matriz productiva vía la desarticulación de las economías regionales y el paso de la agroindustria a los agronegocios.

En este contexto, Murmis (1980) sostenía que la unidad de producción fundada en la combinación de tierra y trabajo familiar, es "la unidad campesina por excelencia". Sin embargo, para el autor ésta no es más que un punto de referencia, ya que el autor creyó positivo para el análisis de las unidades campesinas o con rasgos campesinos la construcción de una tipología donde el límite superior 
esté marcado por un tamaño que no le permita basarse en la renta de la tierra y el inferior enfatice el carácter de "productor" (en otras palabras, unidades cuya significación como productora es limitada por ser muy pequeñas o ya semiproletarias). De aquí que "las unidades campesinas no sólo son parte de un conjunto más amplio [el de pequeños productores], sino también que tienden a estar `en flujo hacia' o 'resistiendo un flujo hacia' otros tipos de unidades productivas que en algo se le asemejan" (Murmis, 1980, p. 2). En esta misma dirección, Pedro Tsakoumagkos (1987) sostenía que el campesinado es funcional al capitalismo pero subordinado al proceso de valorización del capital, subordinación que involucra desde el comienzo a las esferas de la circulación y de la producción campesina.

La implementación de las medidas liberales a partir de la década de 1990, cuya consecuencia será la conformación de un modelo concentrador y excluyente en el agro argentino pero sobre todo para las unidades campesinas, conllevó a que la racionalidad diferencial del campesinado no sea analizada como una faceta inherente a las dinámicas de las unidades campesinas sino a la falta de adecuación de estas al sistema económico imperante. En este contexto, la idea de funcionalidad del campesinado va dejando lugar al concepto de “exclusión”, ya que no es posible seguir pensando en una inserción subordinada de la producción campesina en el sistema, pero funcional al capital agroindustrial.

En este nuevo contexto, el campesinado pasó a ser definido a partir de sus carencias estructurales (la ausencia de niveles de capitalización, producción para la subsistencia, el carácter marginal de su producción, escasez de tierras, etcétera). Autores como Caracciolo Basco (1978), Manzanal (1988 y 1990), Borro y Rodríguez Sánchez (1991), entre otros, relacionaron al campesinado con minifundistas. A su vez, Forni y Neiman (1994), Tsakoumagkos, Soverna y Craviotti (2000) y Murmis (2001), entre otros, relacionaron al minifundista con pobreza rural.

Con el avance del modelo del agronegocio y la situación de exclusión del campesinado del mismo, en el espacio académico como en el de las políticas públicas, la noción de "agricultura familiar" ha 
comenzado a ganar terreno en detrimento del uso de campesinado (Obschatko, Foti y Román, 2006). Asimismo este segundo deslizamiento podemos observarlo en la propuesta del Foro Nacional de la Agricultura Nacional (FoNAF) ya que incluye en una definición de la Agricultura Familiar genérica, a la vez que heterogénea, a "distintos conceptos que se han usado o se usan en diferentes momentos, como son: Pequeño Productor, Minifundista, Campesino, Chacarero, Colono, Mediero, Productor familiar y, en nuestro caso, también los campesinos y productores rurales sin tierra y las comunidades de pueblos originarios" (FoNAF, 2007, p. 9). Así, lo que la teoría social durante años había insistido en delimitar, es decir, al campesinado del chacarero/colono (en el caso argentino), queda unido, ya sea bajo la categoría de pequeño productor familiar -sea capitalizado o no- como en la actualidad bajo la noción de "agricultura familiar". Sin embargo, como sostienen García Guerreiro, Gómez, González, Palmisano y Sabatino: "se trata también del abandono de toda perspectiva que contemple una lógica propia del campesinado dentro de la omnipresente lógica de desarrollo del capitalismo" (2009, p. 7).

En este sentido, creemos que las diferentes definiciones acerca del campesinado en Argentina hacen énfasis en el carácter residual de la economía campesina en el desarrollo capitalista y el difícil devenir de estos sujetos en contextos de integración en los procesos de modernización. Es decir, se produce un conocimiento que es mayormente sobre la descomposición de un sujeto y no sobre su consistencia. A su vez se reflexiona sobre la incapacidad del sistema capitalista y de la modernidad como proyecto occidental de absorber definitivamente las realidades campesinas. En otras palabras, se trata de abordajes epistemológicos sobre este desencuentro que no hacen más que recordar aquella frase de Shanin acerca de la incomodidad del campesinado. Es por ello, que el campesinado es analizado como proceso de extinción o bien de mutación en términos de la lógica del capital.

De aquí que se desprendan dos caminos posibles para las unidades campesinas. El primero de ellos, anclado sobre el carácter improductivo del campesinado, basado en lo que Santos (2000) deno- 
minó la monocultura del tiempo lineal, la cual admite que la historia tiene un sentido, una dirección, marcados por la idea de progreso, modernización, el desarrollo de las fuerzas productivas llevaría a la desaparición de las unidades campesinas y por ende, a la proletarización de los mismos. El otro, anclado en la idea de "interpretar economías de subsistencia como retrazadas y reprimidas, la pobreza 'culturalmente percibida' se ve como la pobreza real" (Cochrane, 2006, p. 1), ha levantado a toda una industria del desarrollo. En efecto, frente a esta situación de exclusión en su faceta socio-económica, como consecuencia del modelo del agronegocio, la respuesta del Estado para atemperar los costos del ajuste fue la implementación de programas estatales -Cambio Rural y el Programa Social Agropecuario, entre otros- que incluyen en sus objetivos lograr una mayor escala a través de la promoción de formas asociativas.

En definitiva, quienes echan mano de categorías tales como, pequeño productor familiar, minifundista, pobre rural, etcétera, acaban por delimitar los trazos de un sujeto en términos de su carencia. Desde tal óptica estamos frente a sujetos limitados o desposeídos de capacidad o agencia; carentes de potencia tecnológica, o incapaces de incorporarla, poseedores de tierras insuficientes, sin aptitudes para integrarse a los mercados y a la gestión productiva, refugiados en su propia pobreza, incompetentes para acumular capital, no viables, etcétera. Estas carencias son colocadas unas veces como atributos del sujeto y otras como resultado de la posición relativa de los mismos en la estructura social. El campesinado aparece entonces como sector irrelevante que sobrevive o busca ampararse en los intersticios o nichos del sistema agroalimentario (participación en el mercado de insumos y productos) y la estructura agraria (participación en la tenencia de la tierra) debido a un avance aún incompleto pero inevitable de las relaciones sociales capitalistas en el agro. Se trata de matices entre aspectos intrínsecos de las unidades o bien de problemas del campesinado dados aspectos estructurales en base a dinámicas sociales que lo excluyen.

Sin embargo, lo que las diferentes definiciones acerca del campesinado han puesto de relieve en términos epistemológicos es 
el carácter colonial y moderno de las ciencias sociales. Por un lado, porque conocer significa cuantificar, aún cuando las cualidades de los objetos no son tenidas en cuenta, y en donde la complejidad del mundo social es reducida a partir de la división y clasificación para luego poder especificar las relaciones sistemáticas entre las partes (Santos, 2000). Es decir, se privilegia cómo funcionan las cosas en detrimento de cuál es el agente o cuál sea el fin de las cosas. Por el otro, porque el sujeto que habla siempre está escondido, es disfrazado, se borra del análisis al igual que su ubicación epistémica. Frente a este desperdicio de la experiencia, como podría sostener Santos (2000), se trata de rescatar la articulación entre los saberes campesinos y sus prácticas. Esto supone desplegar una forma de conocimiento para la cual conocer es reconocer en un sentido que implica elevar al otro (en nuestro caso a las/os campesinas/os) de la condición de objeto a una condición de sujeto (Santos, 2000). Desde este punto de vista epistémico, por un lado, se intenta trascender el dominio global de la ciencia moderna por el conocimiento regulación que trajo consigo la destrucción de muchas formas de saber que volvieron impronunciables las necesidades y aspiraciones de distintos grupos sociales, y por el otro, revalorizar el conocimiento de las realidades campesinas en el marco de una ecología de saberes, en donde el eje está puesto en las articulaciones y las convergencias, en relaciones dialógicas situadas en determinados espacios geográficos y sociales.

\section{LA REGENERACIÓN DEL ESTAR-SIENDO CAMPESINO}

Quizás, desde la vuelta de la democracia, la primera reaparición pública en términos mediáticos y como signo de la existencia de campesinos en Argentina haya sido la publicación en el diario Clarín del conflicto de La Simona (Santiago del Estero), en el año 1998. En esa oportunidad, se trataba de la crónica sobre la resistencia de miembros del Movimiento Campesino de Santiago del Estero al desalojo de sus tierras por parte de un empresario. Dicha noticia daba cuenta no sólo de la conflictualidad en el campo en torno a la propiedad de la tierra, sino también de la existencia de campesi- 
nos organizados en la provincia y en otras regiones del noroeste y noreste argentino. Esta situación, que asombraba a los lectores de un diario porteño de tirada nacional, era la expresión de un proceso organizativo que había comenzado poco después del regreso a la democracia en las provincias de Formosa (Movimiento Agrario Formoseño, antecesor del Movimiento Campesino de Formosa), Misiones (Movimiento Agrario Misionero) y Chaco (Unión de Pequeños Productores de Chaco- UNPEPROCH-), y que luego se expandiera hacia otras provincias. A partir de este hecho, la presencia de noticias sobre el campesinado argentino en los medios de comunicación estuvo relacionada con los conflictos por la tierra.

Con el llamado "conflicto del campo" en el año 2008, la aparición pública en los medios de comunicación de las organizaciones campesinas de carácter nacional (el Movimiento Nacional Campesino e Indígena -MNCI- y el Frente Nacional Campesino -FNC-) ya no se sitúa en la crónica en torno a los conflictos por la propiedad de la tierra sino en un posicionamiento político. En efecto, a través de la publicación de una serie de comunicados, las organizaciones campesinas mostraban no sólo la necesidad de complejizar "el conflicto del campo" más allá de su registro económico al incorporar la cuestión campesina sino que también interrogaban tanto las formas en que había sido concebido "lo campesino" por parte de las ciencias sociales en Argentina como la respuesta del Estado para atemperar la situación de exclusión tanto en su faceta socioeconómica, como consecuencia del modelo del agronegocio, a través de la implementación de programas estatales -Cambio Rural y el Programa Social Agropecuario, entre otros- que incluyen en sus objetivos lograr una mayor escala a través de la promoción de formas asociativas ${ }^{4}$.

\footnotetext{
${ }^{4}$ En términos generales, las políticas de Desarrollo Rural implementadas por el ahora Ministerio de Agricultura, Ganadería y Pesca (MAGYP) han tenido como objetivo "mejorar la calidad de vida y aumentar los ingresos de los pequeños productores tendiendo una malla de contención frente a las políticas de ajuste y desregulación y, complementariamente, modernizar, reconvertir y diversificar las explotaciones para alcanzar niveles de productividad sustentables y con capacidad competitiva" (SAGPyA; 1997, Documento de Estrategia). En este contexto, como sostiene Carballo (2007: 3): [t]al enfoque, con sus más y sus menos se generalizó, e hizo tan "natural", que las propuestas para quiénes son discriminados negativamente o excluidos de los beneficios de las políticas públicas, se efectúan sin tener en cuenta que sólo se está considerando las complejidades existentes en "una de las dos caras de la misma moneda", y que la viabilidad de las mismas depende también de la posibilidad de frenar el avance arrollador del modelo hegemónico.
} 
En efecto, en su discurso público estas organizaciones campesinas hacen hincapié en cuatro proclamas íntimamente relacionadas, que ponen en tela de juicio el tipo de crecimiento y desarrollo económico que propugnan los apologistas de una agricultura de monoculturas industriales o del agronegocio que delinea un sistema agroalimentario global regido por un puñado de transnacionales: la Reforma Agraria, la Soberanía Alimentaria , la Agroecología y lo que podríamos llamar demanda por Justicia Ambiental, lo que incluye una crítica a los efectos del agronegocio, como los desmontes, la contaminación, la pérdida de biodiversidad, entre otros. Estos ejes a los que hacemos referencia se inscriben en el despliegue que presenta a nivel internacional y regional la articulación de organizaciones campesinas. Pero también son asumidos como apuestas por organizaciones locales o de escala nacional que no están articuladas a nivel internacional.

- Reforma Agraria Integral: Con ella se apunta a reinscribir la cuestión del acceso a la tierra al colocar el territorio como centro de demanda y rodear a la dimensión productiva con otras que hacen a la reproducción de un modo de vida, como la cultura y el conocimiento. La propuesta de reforma agraria integral incluye la discusión en torno a la superación de las limitaciones de la propiedad privada, y coloca en el horizonte la exploración de formas de tenencia comunitaria tendientes a conformar una territorialidad campesina, en tanto control colectivo del espacio.

- Soberanía Alimentaria: Se trata de instalar la discusión sobre el qué, el cómo y el para quién de la producción agroalimentaria, que implica recuperar al campesinado en su rol histórico de productor directo de alimentos. Así, se ha configurado un discurso y acciones sobre los derechos a la producción, procesamiento, acopio, comercialización y consumo de alimentos, que con esto último interpela en forma directa a las poblaciones urbanas, sobre todo a las que tienen problemas de acceso a los alimentos en las condiciones que impone el supermercadismo.

- Agroecología: La propuesta agroecológica es tomada por las organizaciones como una alternativa a la agricultura industrial, en gran medida debido a los vasos comunicantes que existen entre aquella y los modelos tradicionales de agricultura campesina e indígena. La autono- 
mía con respecto a los insumos, la integración de actividades productivas diversas, la generación y adopción de tecnologías apropiadas, la revalorización de los conocimientos campesinos, son elementos con gran potencial para el desenvolvimiento de las comunidades.

- Justicia Ambiental: La cuestión ambiental ha ido tomando un mayor peso en los planteos de las organizaciones campesinas e indígenas a partir de los conflictos desatados por los avances de las actividades extractivas en sus territorios. En efecto, el desarrollo de la mega minería, de los desmontes y la expansión de la agricultura industrial han impactado sobre las economías campesinas imposibilitando su desenvolvimiento. Esta situación ha involucrado a las organizaciones campesinas, en articulaciones con el movimiento ambientalista, las asambleas ciudadanas y organizaciones no gubernamentales ecologistas, en la defensa del derecho a un ambiente sano, al acceso igualitario a los bienes naturales comunes y al rechazo de las actividades contaminantes.

Sin embargo, reforma agraria integral, soberanía alimentaria, agroecología y justicia ambiental no sólo son discursos que marcan la posibilidad de irrumpir en el orden de lo dado a través de su distorsión sino que también, ponen en marcha una serie de prácticas y experiencias que, en tanto lógica política, configuran un escenario donde se pone en juego la igualdad o la desigualdad de los interlocutores del conflicto como seres parlantes (Rancière; 1996). En efecto, lo campesino en el país, que se pone de manifiesto en el conjunto de proclamas mencionadas, tiene su correlato subrepticio en una vasta y diversa serie de experiencias y actividades productivas, comunicacionales, comerciales, tecnológicas, entre otras, llevadas a cabo por organizaciones populares del campo en articulación incluso con sectores urbanos.

Es el caso de las múltiples redes de intercambio de productos, que podríamos agrupar dentro de las experiencias de fair trade (comercio justo), pero que en la práctica asumen procedimientos diversos entre sí. Se destaca la "Red de Comercio Justo" de Córdoba que acerca las producciones de las zonas campesinas a la capital provincial, y es co-gestionada por productores, consumidores y estudiantes universitarios. Con un funcionamiento similar están en marcha en 
la Ciudad Autónoma de Buenos Aires y área metropolitana, la "Red Tacurú" y "Puente del Sur", que ofrecen productos de cooperativas, productores familiares y artesanos, y proponen también la formación de núcleos organizados de consumidores. Otro tipo de casos lo constituyen los mercados o puntos fijos de oferta de productos de cooperativas y de grupos campesinos, y son ejemplo destacado de estos el "Mercado de Bonpland" o "El Galpón" ambos en el corazón de la Ciudad Autónoma de Buenos Aires. A nivel de bocas de expendió fijas también cabe mencionar las carnicerías del Movimiento Campesino de Santiago del Estero -Vía Campesina (MOCASE-VC) dispuestas en ciudades intermedias de Santiago del Estero para abastecer a las poblaciones urbanas vecinas a las regiones de mayor densidad de campesinos organizados. No obstante, dentro de las experiencias de intercambio, la más extendida geográfica y socialmente es aquella de las ferias francas. Con amplia cobertura en las provincias del noreste argentino, congregan a productores locales que ofrecen sus productos alimenticios a los consumidores directamente en las cabeceras departamentales donde se arman semanalmente espacios de puestos en plazas o rotondas. En las instancias de intercambio se comercializan o 'truequean' producciones familiares o comunitarias y cooperativas.

En torno de la producción y procesamiento múltiples son las experiencias que reconstruyen sistemas no industriales de manejo de recursos y no capitalistas de organización del trabajo. Estas iniciativas en torno a la producción ponen de manifiesto la heterogeneidad de la producción campesina, así como también el rumbo que se han trazado: fortalecer los encadenamientos productivos que permitan agregar valor a las distintas producciones. Aquí el listado es extenso. Mencionemos algunos como los sistemas silvo-pastoriles, o las fábricas de dulce y conservas, impulsados por las organizaciones campesinas de Santiago del Estero. La horticultura, cultivos locales caso los andinos (maíz y papa andina), miel de monte, hierbas aromáticas y medicinales, ganadería sustentable o trashumante. Con mayor valor agregado cuentan las producciones de vino y salsa de tomate de la Unión de Trabajadores Sin Tierra (UST) de la provincia 
de Mendoza, la harina de algarroba de Santiago del Estero y la yerba mate de Misiones, o el balanceado para animales de granja que se produce en Misiones y Mendoza, o bien, los textiles e hilados que elaboran organizaciones andinas como la Red Puna. Las experiencias que también apuntan a incorporar valor a la cría ganadera o de animales de granja es la producción de chacinados, un ejemplo en tal sentido lo constituyen los chacinados y los medallones de carne de llama de la Red Puna. La producción lechera (bovina y caprina) orientada a la producción de quesos que abastecen a pequeñas y mediana ciudades (un caso emblemático son los quesos y quesillos de Amblayo que llegan al mercado de la ciudad de Salta y constituyen todo un sello de origen y calidad).

Las experiencias en torno a la producción y comercialización de alimentos y productos campesinos cobran cada vez mayor relevancia en la práctica y en el discurso de las organizaciones, en la medida que aquellas son percibidas como una dimensión importante para una reafirmación activa de sus derechos sobre la tierra/territorio. Asimismo, la acción política de las organizaciones en el espacio de la producción y de la comercialización buscan reducir o eliminar la explotación, la desigualdad y la opresión, características básicas de las relaciones sociales en las que se funda la estructura social en el agro argentino, en particular, y el capitalismo, en general. En este sentido, las distintas experiencias de estas organizaciones se proponen transformar relaciones asimétricas tales como la relación productor-acopiador, patrónasalariado, agricultura familiar-agricultura industrial.

En este contexto, aun cuando algunos investigadores consideran a estas experiencias productivas como "economías de la nueva pobreza" (Salvia, 2004), ya que jerarquizan la economía formal por sobre todas otras economías, caracterizándolas de "informales" y por lo tanto, son vistas como meras estrategias adaptativas tendientes a morigerar los impactos de la exclusión y, por ende, como residuales, los emprendimientos productivos y de comercialización de la organización pueden ser consideradas, desde nuestra perspectiva, como "campos de experimentación” (Santos, 2000). Se trata de producir para vivir, en base a valores y prácticas que contradicen la 
lógica de un sistema económico y social altamente excluyente.

Además, los emprendimientos buscan, en base a prácticas agrícolas, ganaderas y forestales que se desarrollan respetando un equilibrio ecológico y social, reducir el impacto de la otra forma de desigualdad de poder dentro de dicho espacio: de la naturaleza por el hombre. Johannes Michelsen (2001) considera que la moderna tecnología puso de manifiesto una dificultosa relación entre el hombre y la naturaleza que va más allá del simple modelo agrícola y que se trata de cuestionar modos de conocimientos, lenguajes, políticas públicas y no sólo una forma de producción. Aquí, por un lado, la forma de producción campesina en tanto "custodia del medio ambiente" implica la conformación de "comunidades normativas", referidas a las reglas y patrones de conducta erigidos como consecuencia de modelos de interacción cotidiana (Barrett; 2000) y que se encuentra estrechamente relacionada con la noción de tiempo, en la medida en que el cuidado del medio ambiente posibilita la reproducción de los recursos naturales y, por lo tanto, de la misma comunidad. Por el otro, abre un espacio de debate entre ella y la economía de mercado, guiada por racionalizaciones monetarias, cuyo objetivo es la maximización de ganancias sin cuestionar las "externalidades" ambientales.

Por otra parte, en los últimos años se han consolidado espacios de intercambio y producción de saberes e innovación tecnológica, estructurados por organizaciones campesinas que en ciertas condiciones coordinan con organismos estatales y/o universidades. Son ejemplos las ferias de semillas que se realizan en distintas provincias siendo la más numerosa en puestos y visitantes aquella que se lleva a cabo en el Parque Pereyra Iraola, Buenos Aires. No obstante existen otras instancias que guardan importancia central en un contexto de renovada reivindicación étnica como son los cambalaches $^{5}$ en las provincias del noroeste argentino. Hace un par de

\footnotetext{
${ }^{5}$ Cambalache refiere a una instancia de intercambio, de trueque, y en tanto tal ha sido una práctica presente en los mundos agrarios andinos. A su vez, distintas comunidades y organizaciones han recuperado el cambalache como espacio de encuentro donde lo sociopolítico, lo cultural y lo económico emergen como unidad. Un caso emblemático en este último sentido es la experiencia de la Red Puna motorizando la "Feria del Cambalache y el Trueque" donde participan comunidades que integran la Red y otras comunidades vecinas. En la $17^{\mathrm{a}}$ edición participaron 500 productores pertenecientes a 40 comunidades indígenas de la Quebrada, Puna y Valles de la provincia de Jujuy, donde se intercambiaron una amplia variedad de productos y se buscó "fortalecer y apoyar la lucha por la tierra y el territorio que lleva adelante la Mesa de Comunidades de las Salinas Grandes y
} 
años en la provincia de Chaco se viene realizando una actividad de gran visibilización campesina. Se trata de la Expo-Campesina que se lleva a cabo en Resistencia, la capital provincial, con la afluencia de miles de visitantes de la ciudad. En todas estas instancias también se difunden los avances en torno de la elaboración de maquinaria social y ambientalmente apropiada a las necesidades campesinas.

El campesinado ha encontrado en el rescate del corpus de conocimiento campesino e indígena su posibilidad de supervivencia. Es cierto que este corpus está compuesto tanto por aquellos saberes que son generados en las comunidades rurales a partir de la observación detallada y sistemática de la naturaleza, y que son transmitidos de generación a generación por la tradición oral y por la práctica en el contexto de la actividad productiva familiar, o en términos generales, en el ámbito de la agricultura campesina (cultivo de varias especies; control de malezas, control de insectos y enfermedades casi sin (o sin) químicos; fertilización orgánica; rotación de cultivos; integración agro-pecuaria-forestal; y uso de recursos y energía locales), como así también por aquellos saberes que pueden ser considerados "conocimiento de otros", es decir, aquellos aprendidos en el trabajo como peones rurales, o aquellos impuestos por organismos estatales que a través de soluciones homogeneizantes pretendían convertir a la comunidad campesina en modernas unidades de producción.

De un destacado interés para las organizaciones campesinas parecieran ser los espacios de formación y comunicación. En esta línea mucho se ha hecho, caso de las escuelas de agroecológica del MNCI tanto en Santiago del Estero como en Mendoza, que paso a paso derivaron en la conformación de la primera universidad campesina (UNICAM) en Ojo de Agua, Santiago del Estero, en el límite con la provincia de Córdoba. Se trata en estos casos de redes de espacios formativos, que se van combinando con la "Escuela de la Memoria" o la "Escuela de Formación Política", que cuentan con la participación de integrantes de organizaciones sociales del campo y la ciudad, de Argentina y Latinoamérica, en el contexto de las

Laguna de Guayatayoc, contra el avance de la minería de litio en la región. Un espacio para reivindicar la vida indígena campesina, nuestros modos de vida, la soberanía alimentaria y la defensa del agua y de las Salinas Grandes". (Ver: http://redpuna.jimdo.com/) 
acciones de la Vía Campesina internacional. Otra herramienta vital son las radios FM del MOCASE-VC, y la red de comunicadores indígenas en Chaco y Formosa.

Finalmente de la mayor importancia son las experiencias de control territorial que se vienen desplegando hace algunas décadas. Las "Reservas" de la UNPEPROCH componen una estrategia de control comunitario efectivo de la tierra con algún status legal. También es de señalarse las parcelas comunitarias del Movimiento Campesino de Córdoba orientadas a la producción conjunta. En un entramado de antiguas y recientes prácticas hallamos las experiencias, del MOCASE-VC, la UNPEPROCH, o Asociación de Pequeños Productores del Chaco (APPPCH), en torno de los campos de pastoreo común que ahora pasan a ser activamente defendidos frente a los cercamientos que conlleva el llamado "avance de la frontera agropecuaria". Con un registro de mayor reconocimiento estatal cuentan las propiedades comunitarias indígenas, que son porciones territoriales vastas, reivindicadas como hábitat ancestral por determinadas comunidades que han logrado -en ciertas oportunidades- titular de este modo.

Los distintos espacios de formación permiten apuntalar, discutir, sistematizar, aquellos saberes que remiten a la relación histórica del campesino con los bienes naturales y las exigencias para la supervivencia campesina; al mismo tiempo que cuestionan las prácticas y saberes que subsumen al campesinado a la lógica del capital. En otras palabras, se trata de la re-legitimación del saber censurado y reprimido por instituciones claramente filiadas al avance del Estado y el capital, erigidas sobre una lógica donde "otras formas de hacer las cosas -de vestirse, de comer, de producir, de intercambiar bienes- no son percibidas y promovidas como manifestaciones de diversidad sino como indicación de incapacidad, de inhabilidad para actuar de acuerdo con el modelo universal y reconocido como válido, es decir, el occidental" (Agostino, 2004).

Sin embargo, no podemos ver a los conocimientos productivos y tecnológicos campesinos como un conjunto de conocimientos y prácticas que no cambian y que solamente se transmiten de generación en generación sin que se produzcan transformaciones, ni en 
el acervo de conocimientos ni en los mismos campesinos. En los espacios de formación, como en las prácticas campesinas, no sólo se evidencian procesos de recuperación y rescate del pasado, sino también procesos de ruptura y resignificación de conocimientos y prácticas a partir de la incorporación de lo nuevo.

Se trata de experiencias que se presentan más o menos deshilvanadas entre sí, desplegándose localmente, o excepcionalmente con alcance regional. No obstante es necesario, como propone Boaventura de Sousa Santos, asumir una posición epistemológica que evite el desperdicio de esta experimentación social. Justamente se trata de dar cuenta de su presencia más allá de sus devenires o resultados evaluados en términos de la razón metonímica. Para ello el autor propone la operatoria de sustituir las cinco monoculturas, como abordaje propio del pensamiento moderno, por cinco ecologías, fundadas en el reconocimiento de los diversos saberes y formas de conocimiento, de la contemporaneidad de múltiples temporalidades, de las diferencias sociales más allá de las jerarquías, de las otras escalas y productividades. De este modo, el conjunto de experiencias que hemos descripto brevemente, con escalas y características tan diversas, pretende ampliar el conocimiento capaz de respaldar la hipótesis de la emergencia del campesinado organizado en Argentina. Una emergencia contingente con dirección incierta, que no obstante insinúa -con pistas y señales- disrupción en el nivel de la sanción estatal de la tenencia privada de la tierra, de la producción en el ciclo de la acumulación ampliada, y de la apropiación industrial de la naturaleza y el trabajo.

\section{CONCLUSIONES}

Las múltiples experiencias de producción, de comercialización, de comunicación -formación, de acceso y manejo a los bienes naturales, de procesamiento, entre otras, llevadas adelante por las organizaciones campesinas nos brindan señales de que la comprensión del mundo campesino es mucho más amplia que aquella propuesta por las ciencias sociales en Argentina, ya que el sentido de 
sus discursos y prácticas generan una discrepancia entre la teoría y la práctica social. De esta manera, en este trabajo más que interrogarnos acerca de las posibilidades de existencia y perpetuación del campesinado, intentamos analizar y comprender, en primer lugar, críticamente la forma en que las ciencias sociales en Argentina han abordado el "tema" campesino. En efecto, no se trata de analizar exclusivamente la capacidad productiva o las hectáreas ocupadas, ni de sumergirnos en discusiones acerca de si el campesinado constituye o no una clase, y si es así en tanto "patatas en un saco de patatas" o si lo es en tanto "clase para sí"; o si por el contrario, los campesinos constituyen una fracción de clase, retardataria, reaccionaria; si este grupo constituye una categoría social integrante de una parte de la sociedad mayor estructurada en clases que se resiste a la modernización; o si por el contrario posee una racionalidad económica que rechaza las tecnologías no apropiadas; si como clase o grupo pertenecía a un régimen de producción ya concluido (como el feudalismo por ejemplo) o si su pervivencia bajo el capitalismo le vale su consideración también capitalista; si constituye un "modo de producción" o sólo es una "sociedad parcial" portadora de una "cultura parcial" (Sevilla Guzmán y González de Molina, 2004).

Si adoptamos la propuesta analítica de Boaventura de Sousa Santos (2000) en dirección a una sociología de las emergencias, nos enfrentamos a una realidad abigarrada, todavía mucho más caótica, aunque más rica. A partir de ahí, comprendimos que "lo campesino", lejos de adquirir importancia académica exclusivamente por los intentos de clasificación de este sujeto social (pequeño productor, campesino pobre, minifundista, etcétera), se explica por sus luchas por tierra y territorio conjuntamente con la revalorización y recuperación de los saberes y prácticas campesinas, que instalan a nivel general el debate sobre el control de los recursos naturales y la relación con la naturaleza, cuestionando la idea moderna que sostiene una distinción total entre naturaleza y sociedad; producir con el objetivo de fortalecer la soberanía alimentaria de las comunidades campesinas, retirándose de aquellos espacios y relaciones económicas que los subordinaba. En otras palabras, se trata, de recuperar lo campe- 
sino en toda la complejidad del sujeto, sin miradas fragmentarias que prioricen una dimensión de la identidad campesina por sobre otras.

Asimismo, lo campesino en Argentina hace visible lo comunitario (no indígena) como forma de control territorial de los recursos naturales, ampliando el alcance de los bienes comunes; pone en evidencia la posibilidad del diálogo entre ciencia y saberes locales en base a la agroecología; y resitúa el lugar de la agricultura en la construcción de una sociedad justa. Y esto es así aunque la emergencia que postulamos, en tanto proceso en marcha, fuera truncada por cualquier motivo.

\section{REFERENCIAS}

AGOSTINO, A. Una Visión Desde El Post-Desarrollo. El derecho a no desarrollarse, 2004 Disponible en http://www.semana83.org.uy/FIN0Textos/Agostino0.htm. Acceso: 21 de abril 2014

BARRETT, G. Solidarity and Exclusion: The Paradox in a rural community. Ponencia presentada al X Congreso Internacional de Sociología Rural, Brasil, 2000.

BORRO, M. del C. y RODRÍGUEZ SÁNCHEZ, C. El minifundio en Argentina. Buenos Aires: Secretaría de Estado de Agricultura y Ganadería, 1991.

CARACCIOLO BASCO, M. y otros. El Minifundio en la Argentina. Primera parte. Grupo Sociología Rural, Buenos Aires: Secretaría de Estado de Agricultura y Ganadería, 1978.

COCHRANE, R. "No son realmente pobres": Ecofeminismo, justicia global y pobreza "culturalmente percibida". Ponencia presentada al Taller "Otro Mundo es Necesario", Centro para la Justicia Global, 2006. Disponible en http://www.globaljusticecenter.org/ponencias2006/ cochraneESP.htm Acceso 27 de febrero 2014.

DELICH, F. Tierra y conciencia campesina, Buenos Aires: Signos, 1970.

DURAND, P. Desarrollo rural y organización campesina en Argentina. El caso del Movimiento Campesino de Santiago del Estero. 2006. Tesis (Doctorado en Ciencias Agropecuarias) Facultad de Agronomía, Universidad de Buenos Aires, Buenos Aires. 
FORNI, F. y NEIMAN, G. La pobreza rural en Argentina. Buenos Aires: Secretaría de Programación Económica, Comité ejecutivo para el estudio de la pobreza en la Argentina, CEPA, 1994.

GARCÍA GUERREIRO, L.; GÓMEZ， C.; GONZÁLEZ， G. D.; PALMISANO, T. y SABATINO, P. Esta agricultura me suena familiar. Contextualizando el debate en torno a la agricultura familiar. Ponencia presentada al Congreso Los movimientos sociales en América latina. Pasado, presente y perspectivas. Mar del Plata, 21 de marzo, 2009.

GIARRACCA, N. y TEUBAL, M. El campo argentino en la encrucijada. Tierra, resistencia y ecos en la ciudad, Buenos Aires: Alianza Editorial, 2005.

GIARRACCA, N. El campesinado en la Argentina: un debate tardío. Realidad Económica. Instituto Argentino para el Desarrollo Económico. Buenos Aires, no. 94, pp.54-65,1990.

MANZANAL, M. El minifundio en la Argentina: políticas alternativas para una realidad poco conocida. $\mathrm{XX}^{\mathrm{o}}$ Congreso Internacional de Economístas Agrícolas. Buenos Aires, 1988.

. El campesinado en la Argentina: un debate tardío o políticas para el sector: una necesidad impostergable. Revista Desarrollo Económico, nº.97, pp.137-152,1990.

MICHELSEN, J. Recent development and political acceptance of organic farming in Europe. Sociologia Ruralis, Vol, n ${ }^{\mathrm{o}} .1$, pp.03-20, 2001.

MURMIS, M. Tipología de pequeños productores campesinos en América Latina, Costa Rica, IICA, Subdirección General Adjunta de Desarrollo Rural, 1980.

- Pobreza rural. Diversidad de situaciones ocupacionales. Buenos Aires: Ministerio de Economía, Secretaría de Agricultura, Ganadería, Pesca y Alimentación, Dirección de Desarrollo Agropecuario. PROINDER, 2001.

OBSCHATKO, E., FOTI, M. del P. y ROMÁN, M. Los Pequeños productores en La República Argentina, Buenos Aires, PROINDER y el IICA, 2006.

POSADAS, M. G. Teoría y sujetos sociales. Algunas consideraciones acerca de los estudios sobre el campesinado en Argentina. Papers. Revista de Sociología. Departament de Sociologia de la Universitat 
Autònoma de Barcelona, nº 57, pp.73-92, 1997.

RANCIÈRE, J. El desacuerdo. Politica y Filosofía, Buenos Aires, Ed. Nueva Visión, 1996.

SALVIA, A. Crisis del empleo y nueva marginalidad en tiempos de cambio social. Génesis de una catástrofe anunciada. Argumentos. Revista de Crítica Social. Instituto de Investigaciones Gino Germani, Universidad de Buenos Aires, n4, s/pp., 2004.

SANTOS, B. de S. Crítica de la razón indolente. Contra el desperdicio de la experiencia, España: Editorial Desclée de Brouwer, 2000.

TSAKOUMAGKOS, P. Sobre el campesinado en Argentina, en Revista Argentina de Economía Agraria. Vol. I, tomo II, 1987.

TSAKOUMAGKOS, P., SOVERNA, S. y CRAVIOTTI, C. Campesinos y Pequeños productores en las regiones agroeconómicas de Argentina. Buenos Aires: Ministerio de Economía, Secretaría de Agricultura, Ganadería, Pesca y Alimentación. Dirección de Desarrollo Agropecuario. PROINDER. (Serie documentos de formulación, $n^{\circ}$. 2), 2000.

\section{OTRAS FUENTES}

http://redpuna.jimdo.com/

http://mnci.org.ar/

http://mocase-vc.blogspot.com.ar/

http://movimientocampesinodecordoba.blogspot.com.ar/

http://ust-mnci.blogspot.com.ar/

http://frentenacionalcampesino.wordpress.com/

http://asambleacampesina.wordpress.com/

Recebido: 05/06/2014

Solicitação de modificações: 1\%07/2014

Aprovação final: 20/07/2014 